\title{
A global ranking of port cities with high exposure to climate extremes
}

\author{
Susan Hanson • Robert Nicholls • N. Ranger • \\ S. Hallegatte · J. Corfee-Morlot • C. Herweijer • \\ J. Chateau
}

Received: 28 July 2009 / Accepted: 6 July 2010 / Published online: 7 December 2010

(C) Springer Science+Business Media B.V. 2010

\begin{abstract}
This paper presents a first estimate of the exposure of the world's large port cities (population exceeding one million inhabitants in 2005) to coastal flooding due to sea-level rise and storm surge now and in the 2070s, taking into account scenarios of socio-economic and climate changes. The analysis suggests that about 40 million people $(0.6 \%$ of the global population or roughly 1 in 10 of the total port city population in the cities considered) are currently exposed to a 1 in 100 year coastal flood event. For assets, the total value exposed in 2005 across all cities considered is estimated to be US $\$ 3,000$ billion; corresponding to around 5\% of global GDP in 2005 (both measured in international USD) with USA, Japan and the Netherlands being
\end{abstract}

S. Hanson $(\varangle) \cdot$ R. Nicholls $(\bowtie)$

School of Civil Engineering and the Environment University of Southampton,

Highfield, Southampton, UK, SO17 1BJ

e-mail: s.e.hanson@soton.ac.uk, r.j.nicholls@soton.ac.uk

S. Hanson · R. Nicholls

Tyndall Centre for Climate Change Research, Southampton, UK

N. Ranger

Grantham Research Institute for Climate Change and the Environment,

London School of Economics and Political Science, London, UK

N. Ranger

Risk Management Solutions Limited, London, UK

S. Hallegatte

Centre International de Recherche sur l'Environnement et Développement

et Ecole Nationale de la Météorologie, Météo-France, Paris, France

J. Corfee-Morlot · J. Chateau

Organisation for Economic Co-operation and Development, Paris, France

C. Herweijer

Price Waterhouse Coopers, London, UK 
the countries with the highest values. By the 2070s, total population exposed could grow more than threefold due to the combined effects of sea-level rise, subsidence, population growth and urbanisation with asset exposure increasing to more than ten times current levels or approximately $9 \%$ of projected global GDP in this period. On the global-scale, population growth, socio-economic growth and urbanization are the most important drivers of the overall increase in exposure particularly in developing countries, as low-lying areas are urbanized. Climate change and subsidence can significantly exacerbate this increase in exposure. Exposure is concentrated in a few cities: collectively Asia dominates population exposure now and in the future and also dominates asset exposure by the 2070s. Importantly, even if the environmental or socio-economic changes were smaller than assumed here the underlying trends would remain. This research shows the high potential benefits from risk-reduction planning and policies at the city scale to address the issues raised by the possible growth in exposure.

\section{Introduction}

Port cities are important concentrations for population with 13 out of the 20 most populated cities in the world in 2005 being port cities. In addition, these cities form a vital component of national and global economies, particularly in developing countries, with a global tripling in the volume of seaborne trade over the past 30 years (UNCTAD 2008). At the same time, these cities are exposed to significant consequences as a result of extreme coastal water level events as demonstrated by Hurricane Katrina (2005). This major storm created significant physical damage on an important port city (New Orleans) causing long run disruption at local to regional scales, but also had social and economic implications at national to global scales (Grossi and Muir-Wood 2006; Hallegatte 2008; Wilbanks et al. 2007). However, despite the consequences of Hurricane Katrina and other extreme events such as Hurricane Ike (2008) and Winter Storm Xynthia (2010), little preparation is being undertaken for the management of such events and their economic implications in the long term (UNFPA 2007).

With projections indicating that, (i) in cities, increases in both absolute population and density are expected to continue during this century (e.g. UNFPA 2007; United Nations 2004a), (ii) the interconnected nature of the global economy will continue and (iii) changes in extreme coastal water levels are inevitable given the commitment to sea-level rise, ${ }^{1}$ future consequences of such extreme events can be expected to be as significant if not greater. In addition, many coastal cities, especially those in deltas, are also predisposed to subsidence, which can be aggravated by human actions, such as drainage of susceptible soils and unsustainable extraction of groundwater (Delinom 2008; Dixon et al. 2006; Nicholls 1995). As shown in New Orleans, this

\footnotetext{
${ }^{1}$ There is debate regarding predictions of sea-level rise but it is recognised that it will continue during this century to thermal expansion of the world's oceans (e.g. Leatherman and Kershaw 2002; Solomon et al. 2007; Wigley 2005).
} 
can be an important factor contributing to an increase in relative water levels and, consequently, a growing flood risk.

In order to comprehend and prepare for the risks that these changes bring globally, it is important to determine the location and extent of current and future exposure. For port cities, this is particularly significant due to their economic importance internationally and the implications of locating future populations and economic development in areas which may become vulnerable to the impacts of extreme events (Guzmán et al. 2009).

The goal of this study is to take a preliminary global overview of coastal flood exposure for world port cities and produce rankings based on population and asset exposure to current and future extreme water levels. This builds on the analysis of Nicholls (1995), but considers a much larger sample of cities to assess relative exposure across world port cities. Exposure rather than 'residual risk' (which includes defences and other adaptation) is considered as people in the flood plain will be at some level of risk even in the best defended of port cities. Failure of existing flood defences due to breaching or overtopping ${ }^{2}$ is always possible. Additionally, data on defences is sparse and no systematic analysis is possible. Effectively, the exposure metric can be viewed as a worst case scenario and exposure can translate into major losses during extreme events. This metric is particularly relevant when considering long timescales, as there is the added uncertainty around the level of defences which will be required and, if available, whether they will be sufficiently maintained to be fully effective.

Two different types of exposure to flood risk are selected - population and assets $^{3}$ - each of which are calculated under current conditions and 2070-2080 (referred to here as 2070s). There are two reasons for this distant timescale. Firstly, it is a long enough timescale that key environmental and socioeconomic factors are significantly different from today and therefore provides a significant change in exposure. Secondly, this is a timescale relevant for planning adaptation measures; many policy choices over land-use and defences, for example, are already locked in for the next few decades yet adopting the right long-term approaches in anticipation of urban growth can prevent many of the environmental problems associated with cities but they need careful planning. The 2070s is a timescale for which current policy choices and debates can influence both exposure and risk.

The analysis considers scenarios for a number of factors which could affect current and future exposure:

1. Population and economic growth;

2. Natural subsidence/uplift;

3. Global sea-level rise;

4. Potential human-induced subsidence.

\footnotetext{
${ }^{2}$ Overtopping refers to seawater flowing over the defences without degrading the defence so as the flood levels diminish after the event, the ingress of water ceases. Breaching refers to the lowering of defences due to various failure mechanisms. This generally allows much larger volumes of water to flood the defended area (Muir Wood and Bateman 2005).

${ }^{3}$ The term 'assets' is generally used here to refer to economic assets in cities in the form of buildings, transport infrastructure, utility infrastructure, physical assets within built infrastructure, vehicles, and other assets. The common unit for monetary amounts in the study is international 2001 US dollars (USD) using purchasing power parities (PPP).
} 
Using these change factors, six main scenarios were investigated to understand changes in exposure given a 100-year return period extreme water level event (i.e. an event with a $0.01 \%$ annual probability). Being based on simple scenarios and methodologies, this analysis does not pretend to forecast or predict future flood exposure in all world cities. Instead, it aims to (i) investigate whether coastal flood exposure may become a more-pressing issue in the future; (ii) gauge possible future exposure levels in business-as-usual scenarios; (iii) identify the main drivers of this exposure and assess the relative importance of environmental changes with respect to socio-economic drivers; and finally (iv) identify the most exposed locations, where more in-depth analysis is necessary and where policy measures are likely to be most beneficial.

\section{Methodology}

The estimation of population/urban area change related to environmental change at the global scale is difficult due largely to the data available (e.g. Small and Nicholls 2003; Vafeidis et al. 2008). Environmental and population data of a consistent quality, suitable resolution and covering the required parameters are limited, restricting the ability to achieve precise, accurate results (Guzmán et al. 2009). For city-based investigations there are also the widely varying definitions of the spatial extent of urban areas which can lead to difficulties in generating comparable statistics for individual towns and cities. Consequently, the methodology adopted for this study was to use the most comprehensive data available at the global scale in a consistent manner making clear reasonable assumptions where necessary.

The investigation took the form of an elevation-based GIS (Geographical Information Systems) analysis, after McGranahan et al. (2007), following the methodology shown in Fig. 1.

City selection was limited to coastal urban agglomerations with populations greater than one million, as reported in United Nations (United Nations 2005) which are also recognised ports. Following identification, population distribution was obtained from the Landscan 2002 Global Population Database. The LandScan data set is a worldwide population database and is currently one of the best population datasets available (Sabesan et al. 2007). It provides ambient (the average population for a given location over $24 \mathrm{~h}$ ) populations, and is widely used for assessing exposed or 'at risk' populations should an area be subject to an extreme event. Determination of city extents from this data was based on available post code data. The population distribution within the postcode-defined areas was then mapped onto $90 \mathrm{~m}$ resolution topographic data from the Shuttle Radar Topography Mission (SRTM), giving a horizontal map of geographical cells with defined population and elevation. From this population totals by elevation for each city were obtained. The assumption of linear distribution for the population within each elevation then allowed narrower bands to be created which could reflect any changes in extreme water level. Population exposure was then calculated as a function of elevation against water levels related to the 1:100 year storm surge. Water level data were determined from the DIVA (Dynamic Interactive Vulnerability Assessment) database (Vafeidis et al. 2008). Exposed population was then transposed into exposed assets using a widely used assumption in the insurance industry that, as urban areas are typically more affluent than rural 


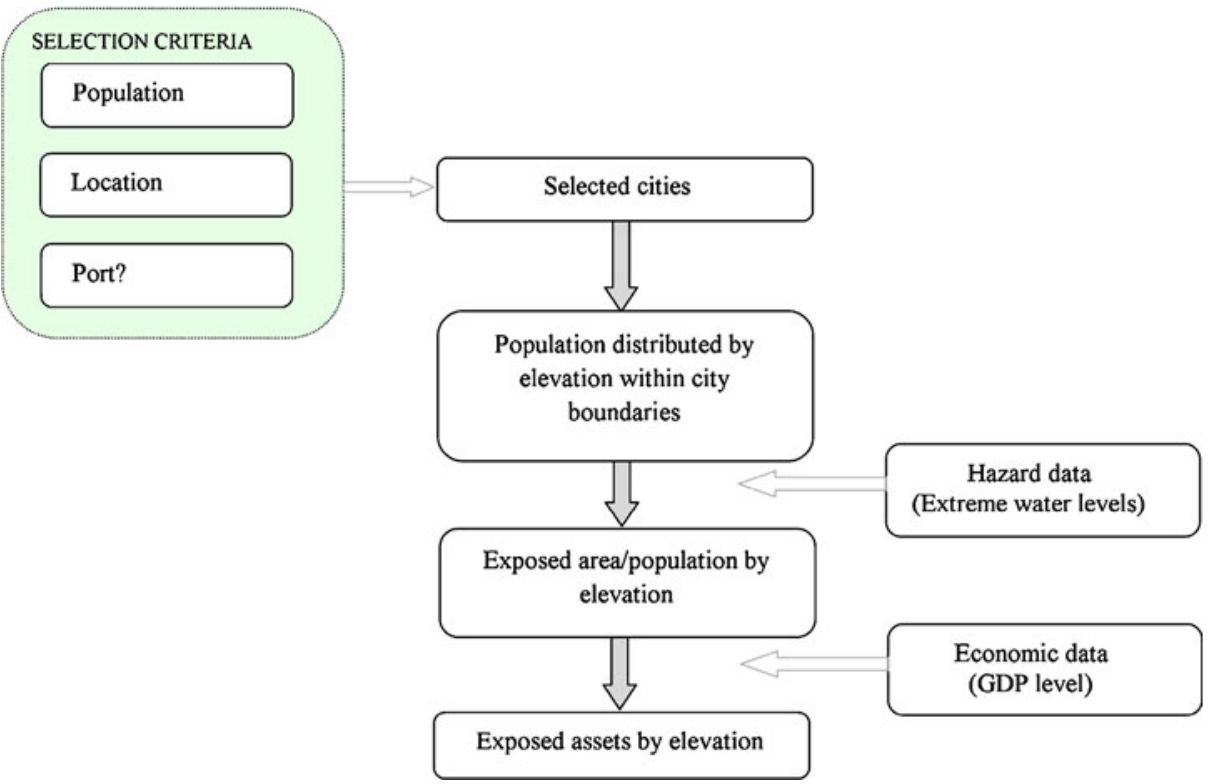

Fig. 1 Methodology adopted to produce ranking of city vulnerability to coastal flooding

areas, each person in a city has assets that are 5 times the annual Gross Domestic Product (GDP) per capita. The calculation of assets was based on the national per capita GDP Purchasing Power Parity (PPP) values for 2005 the International Monetary Fund database (available online at www.imf.org). PPP values were used as this is a standardised value and is recognised as a good indicator for economic comparison. Cities were then ranked from highest to lowest exposure for either population or assets.

Recognising both the scoping nature of the study and the debates surrounding the precise location and magnitude of changes in the factors driving changes in water level, a scenario based approach was used for future changes in extreme water levels. A number of scenarios are created based on combinations of drivers of changes in water levels and socio-economic scenarios; only two are discussed here and are shown in Table 1. Change in water level is a function of sea-level rise, enhanced storms and subsidence (where appropriate).

Table 1 Summary of the scenarios used to analyse the 100 year flood event

\begin{tabular}{|c|c|c|c|c|c|c|}
\hline \multicolumn{2}{|c|}{ Scenario } & \multicolumn{4}{|l|}{ Water levels } & \multirow{3}{*}{$\begin{array}{l}\text { Population } \\
\text { and economy }\end{array}$} \\
\hline \multirow[t]{2}{*}{ Code } & \multirow[t]{2}{*}{ Description } & \multicolumn{2}{|l|}{ Climate } & \multicolumn{2}{|c|}{ Subsidence } & \\
\hline & & $\begin{array}{l}\text { Global sea- } \\
\text { level rise }\end{array}$ & $\begin{array}{l}\text { Storm } \\
\text { enhancement } \\
\text { factor }\end{array}$ & Natural & Anthropogenic & \\
\hline$\overline{\mathrm{C}}$ & Current city & $\mathrm{X}$ & $\mathrm{X}$ & $\mathrm{X}$ & $\mathrm{X}$ & Current \\
\hline FAC & $\begin{array}{l}\text { Future city, } \\
\text { all changes }\end{array}$ & $\sqrt{ }$ & $\sqrt{ }$ & $\sqrt{ }$ & $\sqrt{ }$ & Projected \\
\hline
\end{tabular}


As future changes in global sea level are uncertain and data inclusive of the significant local variations is limited, the present analysis assumes a homogenous global rise of $0.5 \mathrm{~m}$ above current levels by 2070. This is in the upper range of IPCC projections (IPCC 2007) and well within the ranges of other projections (e.g. Rahmstorf 2007). The storm enhancement factor (reflecting the potential increase in extreme water levels due to more intense storms) was developed as part of this study; for tropical storms a $10 \%$ increase in extreme water levels was assumed, with no expansion in affected area; while for extratropical storms, a 10\% increase in extreme water levels was assumed between $45^{\circ}$ and $70^{\circ}$ latitude. Information on annual rates of anthropogenically induced subsidence is also extremely limited, consequently a uniform $0.5 \mathrm{~m}$ decline in land levels was assumed from 2005 to the 2070s in those cities which are historically susceptible, commonly port cities located in deltas. Together, this approach gives a variable change in extreme water level from roughly $0.5 \mathrm{~m}$ in cities only affected by global sea-level rise, to as much as $1.5 \mathrm{~m}$ for those cities affected by global sea-level rise, increased storminess and human-induced subsidence.

Socio-economic projections were derived from recent OECD ENV-Linkages model analysis (Burniaux and Chateau 2008; OECD 2008) and have been extended to the end of the century for this analysis. OECD population projections are based upon UN "medium variant" projections to 2050 (United Nations 2004b). In this variant, the global population stabilises at around 9 billion by mid-century, which is about $50 \%$ higher than the current population. Between 2050 and 2080 national population growth rates are extrapolated forward with the exception of a few regions. In Japan, Russia and countries within eastern European region, the UN projects rapid rates of decline in population to 2050. For these regions, the OECD baseline projection assumes that the rates of decline slow significantly in the last half of the century. For these aggregate regions, the OECD baseline is generally consistent with population projections found in post-SRES medium scenario outcomes (Fisher et al. 2007). This economic scenario represents a baseline scenario, with no climate change impacts or climate policies, both of which could influence significantly GDP, assets, population distribution and, therefore, risk levels in cities.

The population in the cities in 2070s depends on three factors: (1) the projection of regional population; (2) change in urbanization rate; (3) specific properties of the city. This analysis uses population projections for each OECD region, taken from the OECD baseline scenario in 2075. The UN provides a projection of urbanization rates for all countries up to 2030. The 2005-2030 trends in urbanization rate have been used to extrapolate urbanization rates in 2075, assuming that urbanization rates will saturate at $90 \%$, except where it is already larger than this value (e.g. in special cases like Hong Kong). As the investigation of variations in urbanisation rates within countries was beyond the scope of this study, the city projections assume that the population of all cities within a given country will grow at the same rate and that new inhabitants of cities in the future will have the same relative exposure to flood risk as current inhabitants. This means that by the 2070s, six coastal cities are larger than any city today (>35 million people) and Mumbai, Dhaka, Karachi and Lagos exceed 50 million people. While it is recognised that the urban footprint of any city may expand over time, this study had adopted the premise that city administration boundaries are fixed and in effect any increase in population will result in an increase 
in density in proportion to that experienced currently. Projected populations were distributed accordingly.

For asset exposure in the 2070's, the analysis is based on the same OECD ENVLinkages population projections (OECD 2008). The analysis assumes that the GDP for all cities within a given country grow at the same rate. Urban GDP per capita is assumed to grow at the same rate as the relevant national (or regional) GDP per capita trends throughout the period 2005 to 2075 . While this baseline portrays only one possible future, it is sufficient to illustrate the interaction between development and climate change in the 2070 s timeframe explored here.

The full methodology, data and range of scenarios used in the study are detailed in Nicholls et al. (2007).

\section{Results}

The analysis begins from a dataset of 136 ports, which were found to fit the initial selection criteria. The global distribution is concentrated in Asia (52 ports or 38\%) with China (14 ports or 10\%) and the USA (17 ports or 13\%) being the largest individual countries (Fig. 2). The majority are classed as seaports/harbours (119), which includes 16 deepwater ports and two oil terminals. Seventeen river ports in the coastal zone were identified, ranging in size from small (e.g., Hai Phong and Thành Pho Ho Chi Minh in Vietnam) to very large (e.g., Philadelphia and New Orleans in the USA). All the coastal cities with river ports are at elevations and locations where they are affected by storm surges today, and will therefore also be affected by sea-level rise: important examples include Dhaka and Kolkata (cf. Munich Re 2004). Thirty-seven of the port cities are either entirely or partially in deltaic locations. Where a city was associated with more than one port, for example Tokyo incorporates the ports of Tokyo, Chiba and Yokohama, it is treated as a single city in the analysis. In addition, some cities could have been amalgamated for analysis purposes as they are adjacent, such as Hong Kong and Guangzhou (e.g. Munich Re

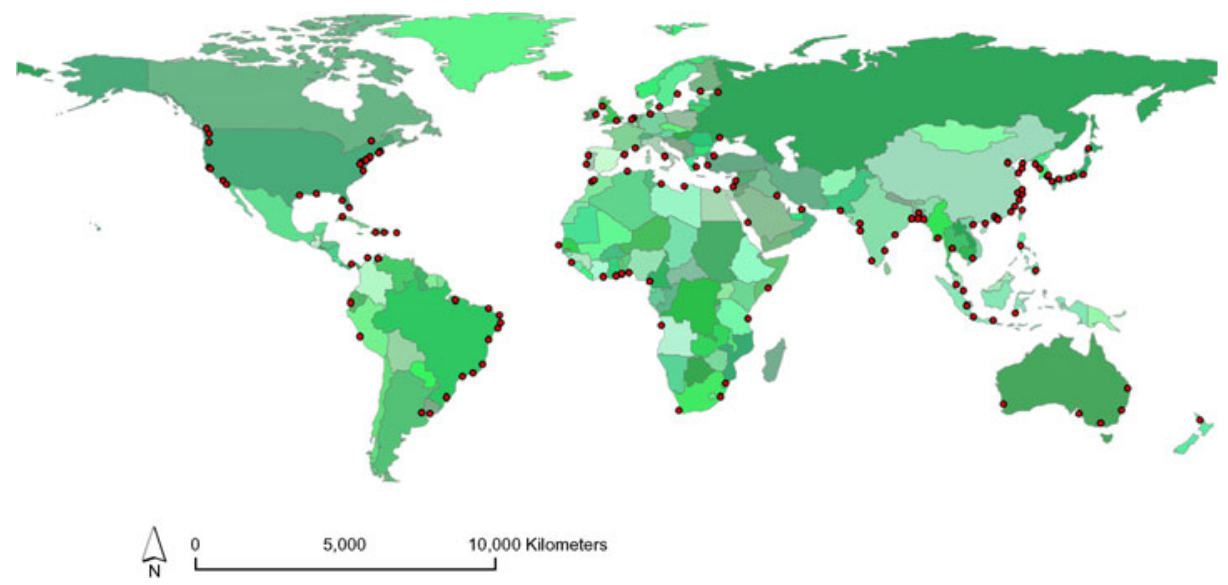

Fig. 2 The location of the 136 port cities analysed in this study 
2004) but this analysis follows the definitions in the United Nations (2005) city data throughout.

The exposure results discussed in this paper focus on the current situation (scenario C) and the 2070's extreme scenario (FAC), described in Table 1. Findings presented here are focus on the Top 20 ranked cities for the two exposure measures. Further analysis and the full list of port cities with all exposure data are downloadable from http://www.oecd.org/env/cc/cities.

\subsection{Global, regional and national exposure}

Globally, the total number of people currently exposed in the 136 cities is approximately 38.5 million ( $0.6 \%$ of the global population or roughly 1 in 10 of the total port city population in the cities considered here). As shown in Fig. 3, Asia has a significantly higher number of people living beneath the 100-year water level, with $65 \%$ of the global exposed population, whilst South America and Australasia have relatively low exposure: $3 \%$ and $<1 \%$ of the global total, respectively. This reflects both the high number of port cities in Asia and the high exposure per city, when compared to other continents. By the 2070s, total population exposed could grow more than threefold to around 150 million people due to the combined effects of climate change (sea-level rise and increased storminess), subsidence, population growth and urbanization. Asia remains the most exposed in terms of population (see Fig. 3) and Africa's total exposed population has increased significantly to more than the USA and Europe. Twelve countries contain $90 \%$ of the total 148 million of people exposed, notably in China (21\%), India (11\%), Bangladesh (12\%), USA (9\%), Vietnam (9\%), Japan (5\%), Thailand (3\%), and as well as Myanmar (3\%), Egypt (3\%), Cote d'Ivoire (2\%),Nigeria (2\%) and Indonesia (2\%).

The monetary value of assets exposed to a 1 in 100 year extreme water level, globally is estimated to be US\$3,000 billion today; corresponding to around $5 \%$ of global GDP in 2005 (based on purchasing power parities-PPP). North America has the largest value of assets exposed (Fig. 3) largely because the per capita GDP (PPP) is substantially higher than most other countries. The bulk of exposed assets in Asia are currently concentrated in Japan. In the future, the total value of assets exposed is projected to grow rapidly, reaching US $\$ 35,000$ billion by the 2070s; more than ten times current levels and rising to roughly $9 \%$ of projected global GDP in this period. Asia is projected to have the highest asset value at risk, changing places with North America, while the other continents maintain their relative exposure. Nationally, the exposure analysis reveals that $90 \%$ of the total estimated 2070s asset exposure across the 136 cities is concentrated in only eight countries (China, USA, India, Japan, Netherlands, Thailand, Vietnam and Bangladesh) (Fig. 4).

The relative contributions of the different drivers of exposure growth differ by location. Overall, environmental changes (including increased storminess and sea level rise), increase population exposure by around $35 \%$, with the largest contribution being from relative sea-level rise (24\%). Human-induced subsidence increases overall exposure by around $14 \%$ although only 36 of the 136 ports were considered susceptible to this driver. The potential impact related to human-induced subsidence is already evident in several Asian cities, which have been historically susceptible e.g. Kolkata, Dhaka, Shanghai and Bangkok (Nicholls 1995). If all the influences on 

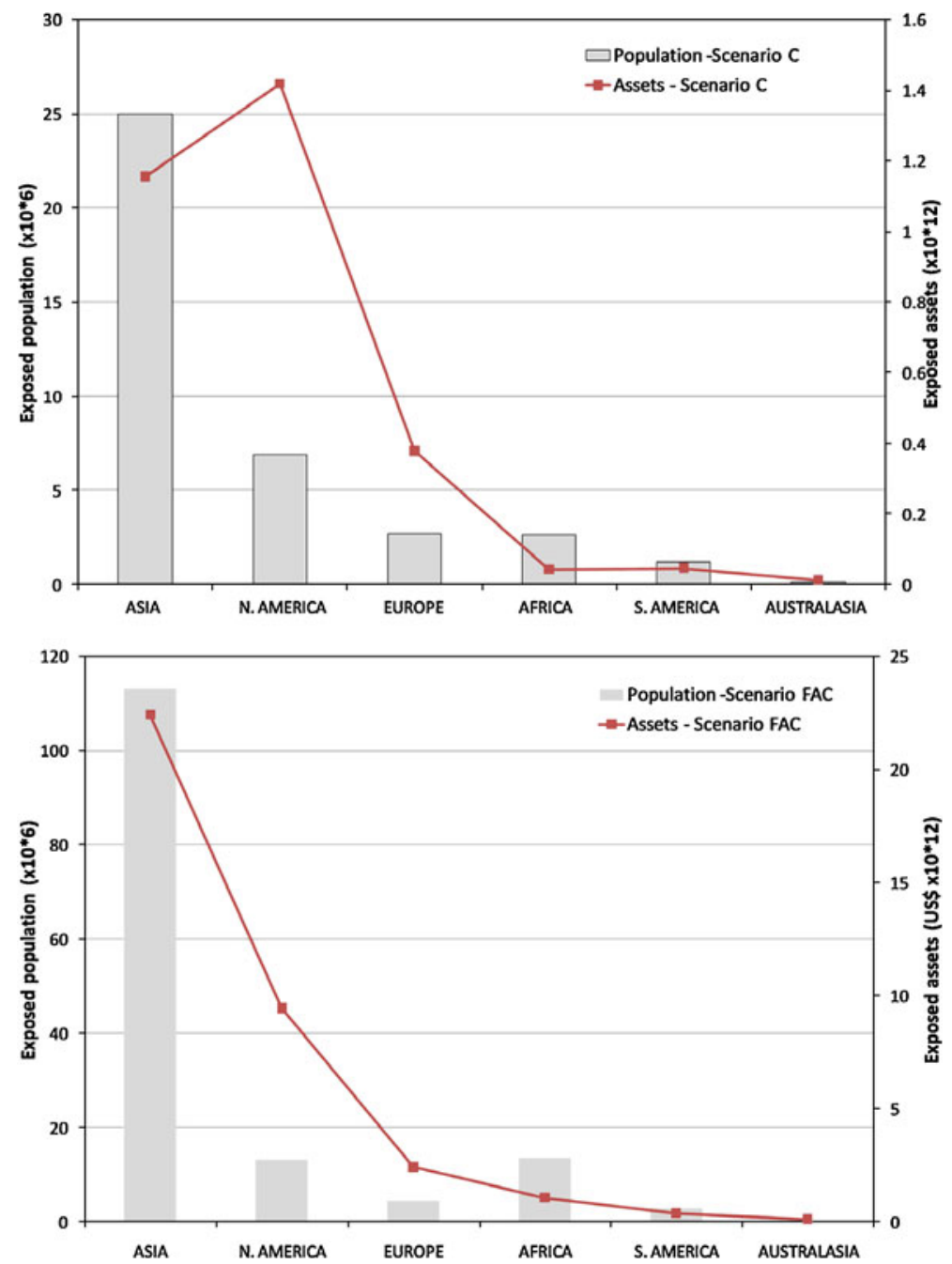

Fig. 3 Total population and assets exposed to extreme water levels by continent (scenarios $\mathrm{C}$ and FAC)

extreme water level by the 2070 s are combined with the baseline population, the exposed population grows to 59 million by the 2070s: an increase of about $50 \%$. Incorporating population growth projections increases this figure to 148 million (an increase of about $150 \%$ ) representing a threefold increase in exposure by the 2070 s. In terms of assets, the role of socio-economic drivers is larger: without any increase in water levels, asset exposure could already grow eightfold. However, water levels do contribute to additional asset exposure and they could be responsible for about one third of the growth in asset exposure in the 2070s. In general, exposure change in developing country cities is more strongly driven by socioeconomic changes, while developed country cities see a more significant effect from climate change (see Fig. 4). 


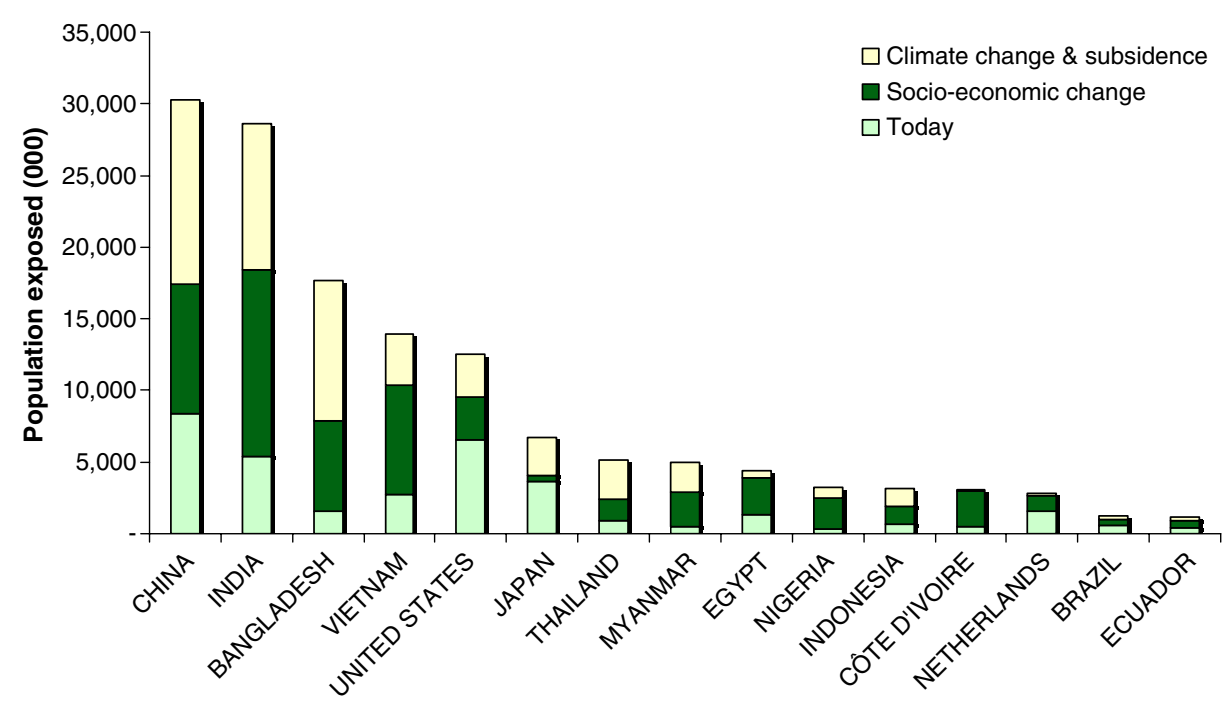

Fig. 4 Population exposure for the top 15 countries in the 2070s under scenario FAC showing the proportions associated with current exposure, climate change and subsidence and socio-economic change

Looking at the level of individual cities, population and asset exposure is concentrated in relatively few cities (see Fig. 5); over $50 \%$ of the exposed population and assets are found in the top ranked $10 \%$, and more than $70 \%$ in the top 20 of the 136

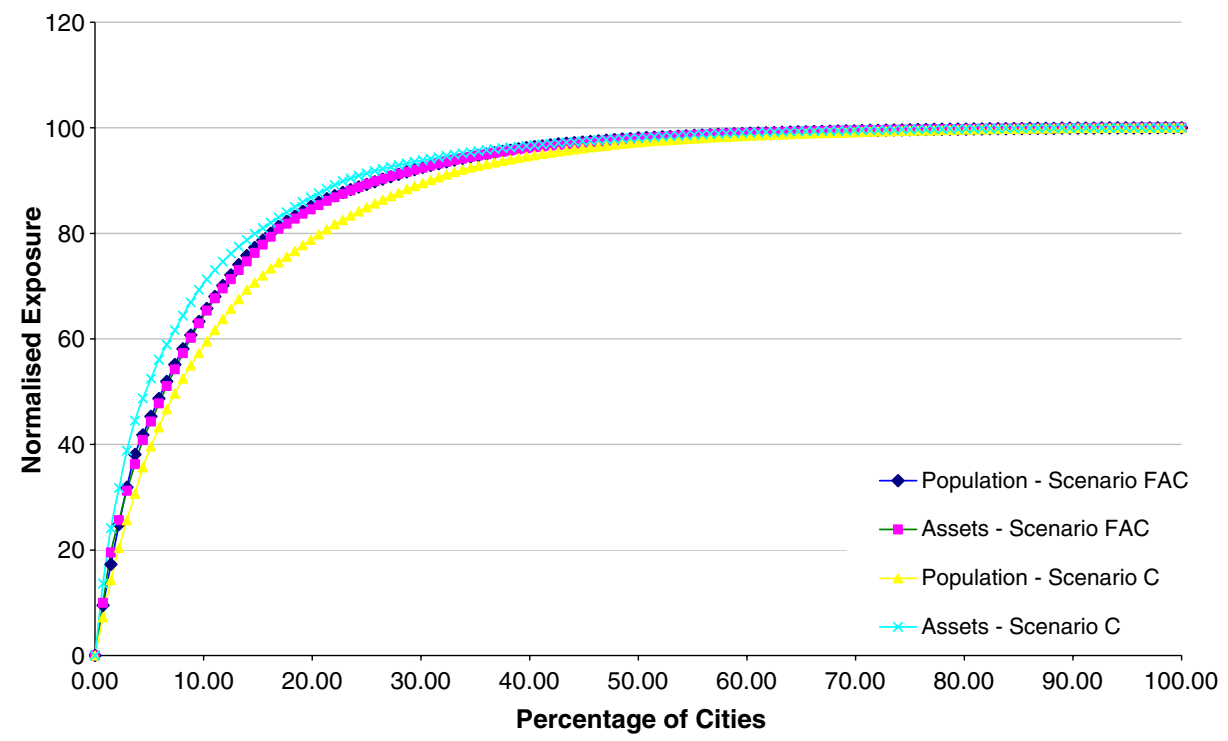

Fig. 5 Cumulative distribution of total exposure for the current situation and 2070s (scenarios C and FAC) 
port cities. The following discussion therefore focuses on those cities ranked in the Top 20 for each of the scenarios.

\subsection{Ranking by population}

In the current situation and in the projected scenario, the Top 20 cities for population exposure are disproportionately located in deltas, with 13 and 17 cities identified as being in deltaic locations respectively. Asia contains a high proportion $(\geq 65 \%)$ of the Top 20 rankings, especially in the 2070 s, because of urbanization and population growth (Fig. 6).

Nonetheless, the Top 20 include cities in both developed and developing countries. Climate change and human-induced subsidence increase the absolute size of the exposed population, but many of the same cities remain in the Top 20 rankings irrespective of the changes (although with different order). Top 20 cities in both current and future rankings include Mumbai, Guangzhou, Shanghai, Miami, Ho Chi Minh City, Kolkata, New York, Osaka-Kobe, Alexandria, Tokyo, Tianjin, Bangkok, Dhaka and Hai Phong (see Table 2).

In addition to absolute numbers, the growth in exposure is also relevant. Figure 7 shows the 20 cities with the greatest rate of increase in population exposed out of the top 50 cities most exposed to present-day extreme sea levels. Each of the top 20 are projected to see more than a $200 \%$ increase in exposure. Although these 20 cities are all in developing regions, 17 in Asia (including four country capitals), and three in Africa (two being capitals), a number of other cities, not present in the top 50 for current population exposure, see significant proportional increases in exposure. These include many African cities, such as Mogadishu in Somalia and Luanda in Angola. While these cities are not expected to experience the highest absolute increases in exposure, their significant proportional increase could lead to flood management challenges within the city. The highest relative increase is seen in

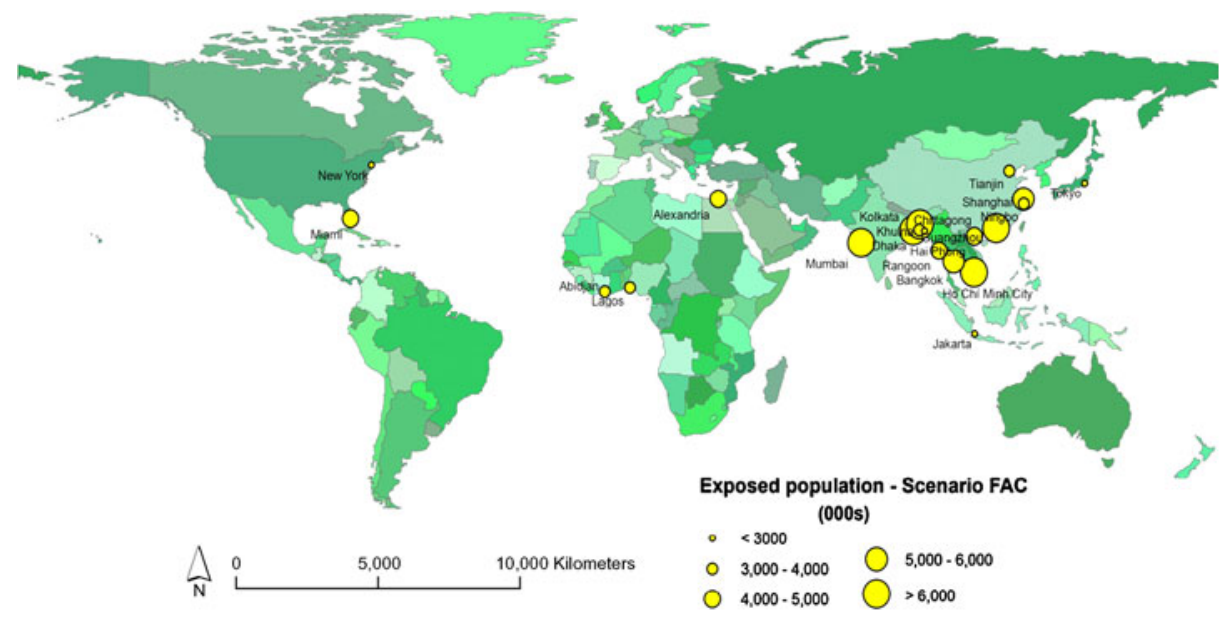

Fig. 6 Map showing the top 20 cities for exposed population under scenario FAC-2070s with climate change 
Table 2 Top 20 cities ranked in terms of population exposed to coastal flooding in the 2070s (including both climate change and socioeconomic change) and showing present-day exposure

\begin{tabular}{lllrl}
\hline Rank & Country & Urban agglomeration & $\begin{array}{r}\text { Exposed population- } \\
\text { current (C) }\end{array}$ & $\begin{array}{l}\text { Exposed population- } \\
\text { future (FAC) }\end{array}$ \\
\hline 1 & India & Kolkata (Calcutta) & $1,929,000$ & $14,014,000$ \\
2 & India & Mumbai (Bombay) & $2,787,000$ & $11,418,000$ \\
3 & Bangladesh & Dhaka & 844,000 & $11,135,000$ \\
4 & China & Guangzhou & $2,718,000$ & $10,333,000$ \\
5 & Vietnam & Ho Chi Minh City & $1,931,000$ & $9,216,000$ \\
6 & China & Shanghai & $2,353,000$ & $5,451,000$ \\
7 & Thailand & Bangkok & 907,000 & $5,138,000$ \\
8 & Myanmar & Rangoon & 510,000 & $4,965,000$ \\
9 & USA & Miami & 2,003 & $4,795,000$ \\
10 & Vietnam & Hai Phòng & 794,000 & $4,711,000$ \\
11 & Egypt & Alexandria & 1,330 & $4,375,000$ \\
12 & China & Tianjin & 956,000 & $3,790,000$ \\
13 & Bangladesh & Khulna & 441,000 & $3,641,000$ \\
14 & China & Ningbo & 299,000 & $3,305,000$ \\
15 & Nigeria & Lagos & 357,000 & $3,229,000$ \\
16 & Côte d'Ivoire & Abidjan & 519,000 & $3,110,000$ \\
17 & USA & New York-Newark & $1,540,000$ & $2,931,000$ \\
18 & Bangladesh & Chittagong & 255,000 & $2,866,000$ \\
19 & Japan & Tokyo & $1,110,000$ & $2,521,000$ \\
20 & Indonesia & Jakarta & 513,000 & $2,248,000$ \\
\hline & & & &
\end{tabular}

Qingdao in China, which is projected to experience a $2000 \%$ increase in exposure (although its absolute exposure remains below the Top 20 at $1.8 \mathrm{~m}$ people in the 2070s). The rapid increase in exposure in these cities reflects the effect of the strong population growth and urbanisation expected in Africa and Asia.

\subsection{Ranking by exposed assets}

The wealthiest countries (as represented by the GDP (PPP)) currently dominate the rankings in terms of asset exposure. ${ }^{4}$ When looking at the assets currently exposed to extreme water levels (scenario C), the Top 10 are all located in the USA, Netherlands or Japan and represent over $60 \%$ of the top 50 cities' vulnerable assets. About $90 \%$ of the total estimated 2070s asset exposure across the 136 cities studied is concentrated in China, USA, India, Japan, Netherlands, Thailand, Vietnam and Bangladesh (Fig. 8 and Table 3). In the current context, Mumbai and Kolkata, which appear at the top of the population rankings, rank much lower for assets, falling just inside the Top 20.

In terms of the percentage increase in assets exposed (Fig. 9), all but one of the top 20 cities is an Asian city. The exception is Miami at rank 20. The increases in assets exposed are in round terms an order of magnitude larger than the increases in population exposed. Each of the top ten cities is projected to experience a more

\footnotetext{
${ }^{4}$ Note: the fact that the wealthiest countries dominate the ranking in terms of asset exposure does not imply that welfare losses are larger in these countries, since they have much stronger resources to protect against, prepare for and cope with floods.
} 


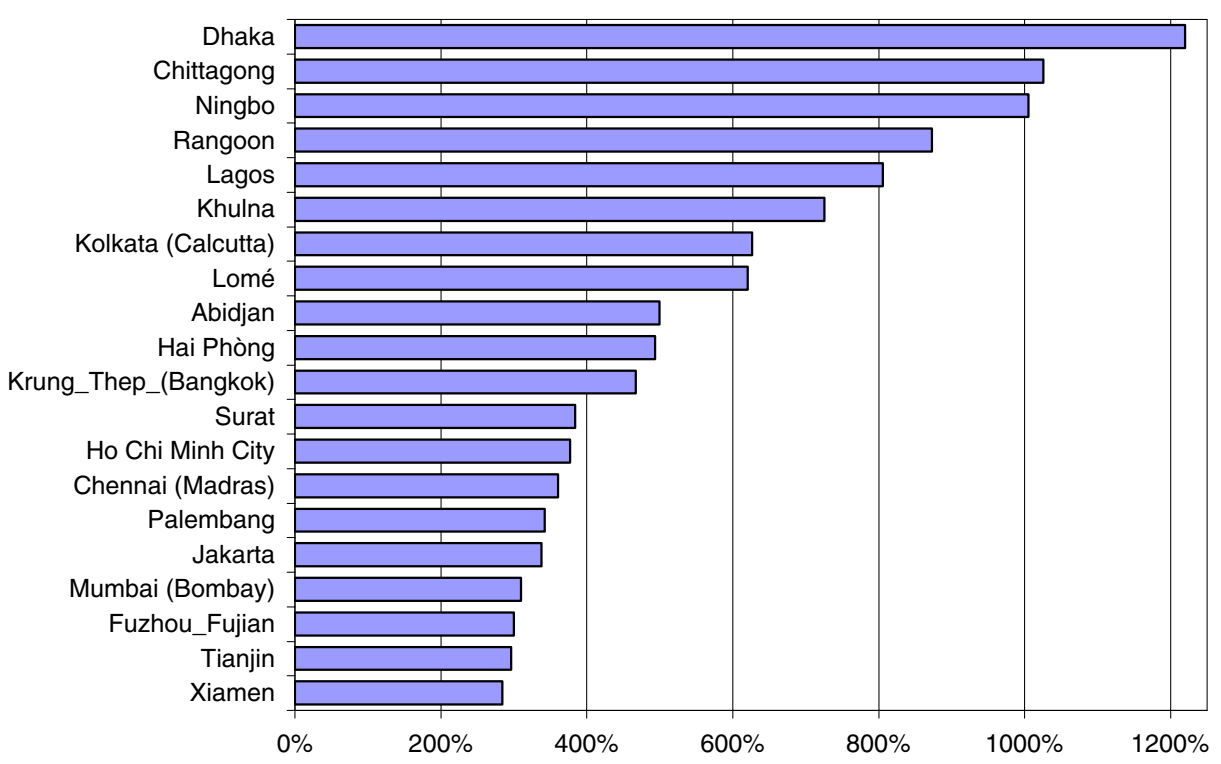

Fig. 7 Top 20 cities with the highest proportional increase in exposed population by the 2070s under the FAC scenario (2070s) relative to the $\mathrm{C}$ scenario. Cities were selected from cities with the highest exposure under scenario $\mathrm{C}$

than 30-fold increase in assets exposed. The top three cities, Ningbo (China), Dhaka (Bangladesh) and Kolkata (India), are projected to see a more than 60-fold increase in exposure. This striking increase in asset exposure is driven by the large increases in wealth and population projected in Asian cities.

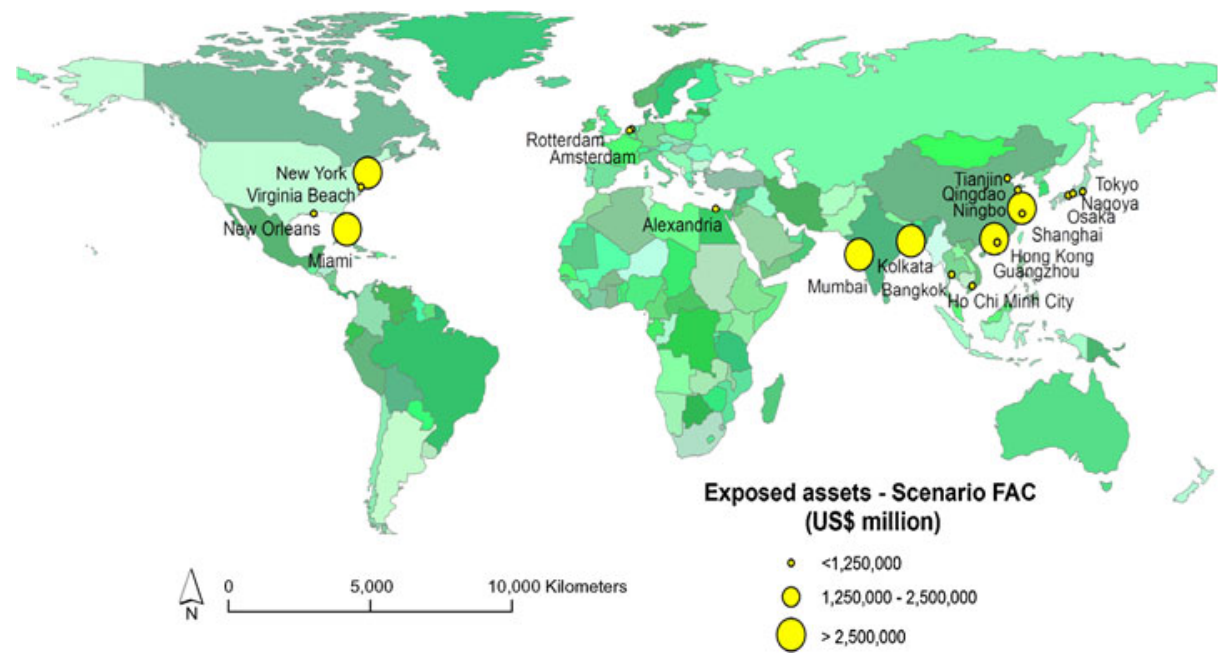

Fig. 8 Map showing the top 20 cities for exposed assets under scenario FAC-2070s with climate change 
Table 3 Top 20 cities ranked in terms of assets exposed to coastal flooding in the 2070s (including both climate change and socioeconomic change) and showing present-day exposure

\begin{tabular}{lllrl}
\hline Rank & Country & Urban agglomeration & $\begin{array}{c}\text { Exposed assets- } \\
\text { current }(\text { \$Billion) }\end{array}$ & $\begin{array}{l}\text { Exposed assets- } \\
\text { future (\$Billion) }\end{array}$ \\
\hline 1 & USA & Miami & 416.29 & $3,513.04$ \\
2 & China & Guangzhou & 84.17 & $3,357.72$ \\
3 & USA & New York-Newark & 320.20 & $2,147.35$ \\
4 & India & Kolkata (Calcutta) & 31.99 & $1,961.44$ \\
5 & China & Shanghai & 72.86 & $1,771.17$ \\
6 & India & Mumbai & 46.20 & $1,598.05$ \\
7 & China & Tianjin & 29.62 & $1,231.48$ \\
8 & Japan & Tokyo & 174.29 & $1,207.07$ \\
9 & China & Hong Kong & 35.94 & $1,163.89$ \\
10 & Thailand & Bangkok & 38.72 & $1,117.54$ \\
11 & China & Ningbo & 9.26 & $1,073.93$ \\
12 & USA & New Orleans & 233.69 & $1,013.45$ \\
13 & Japan & Osaka-Kobe & 215.62 & 968.96 \\
14 & Netherlands & Amsterdam & 128.33 & 843.70 \\
15 & Netherlands & Rotterdam & 114.89 & 825.68 \\
16 & Vietnam & Ho Chi Minh City & 26.86 & 652.82 \\
17 & Japan & Nagoya & 109.22 & 623.42 \\
18 & China & Qingdao & 2.72 & 601.59 \\
19 & USA & Virginia Beach & 84.64 & 581.69 \\
20 & Egypt & Alexandria & 28.46 & 563.28 \\
\hline
\end{tabular}

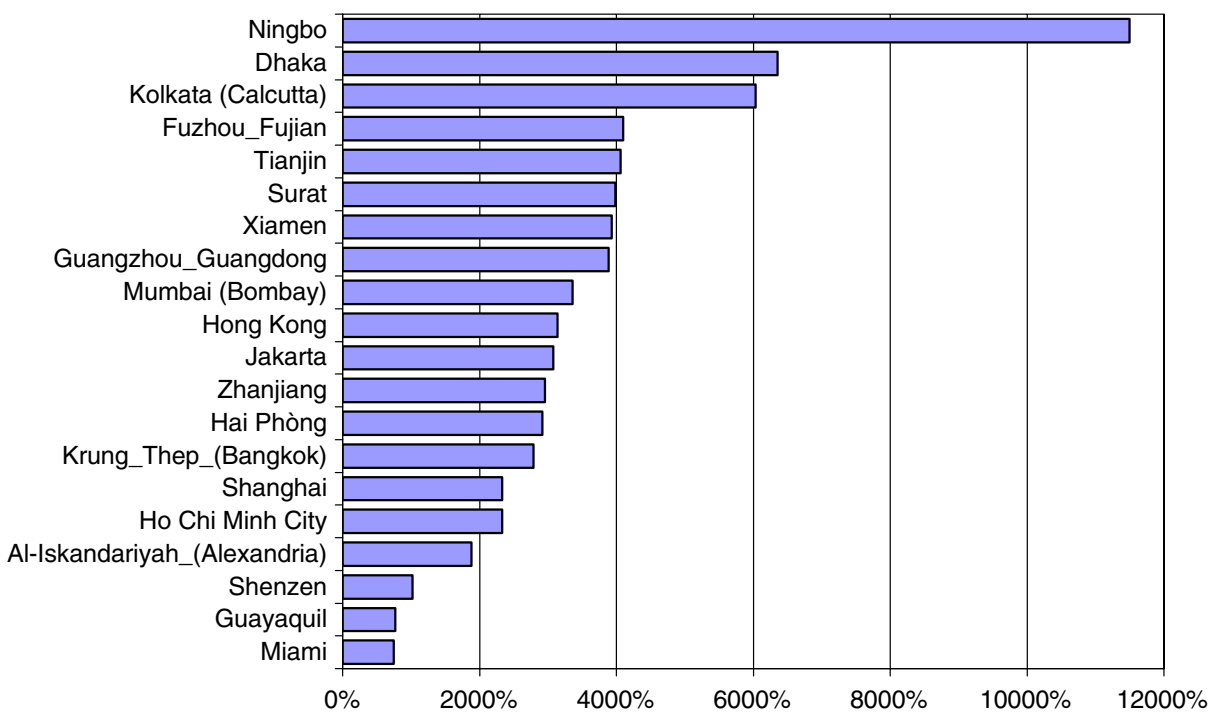

Fig. 9 Top 20 cities with the highest proportional increase in exposed assets by the 2070s under the FAC scenario relative to the current situation. Cities were selected from cities with the highest exposure in 2005 
As with population exposure, there are a number of cities that experience high proportional increases in assets exposed, while their absolute value of assets exposed is relatively low. This includes a number of African cities, as well as smaller Asian cities. Ningbo, China, is projected to see the largest proportional increase in assets exposed. Unlike population exposure, no cities are expected to see a decrease in assets at risk as wealth increase is projected everywhere. ${ }^{5}$

\section{Risk management}

This study recognises that exposure does not automatically translate into risk, and it is therefore important to consider protection and adaptation strategies. Cities are often developed behind natural defences or on relatively high ground, however as they increase in size and wealth there is a trend towards building in more hazardous locations and a growing dependence on artificial defences over time. For the port cities, adapting port and harbour areas to changing conditions will be vital to maintaining the economies of both the cities and the countries they serve. Adaptation strategies encompass a range of policy options-from an immediate response to longer-term options-and commonly include the following:

(i) Early warning systems and evacuation;

(ii) Upgraded protection;

(iii) Managing subsidence (in susceptible cities);

(iv) Building regulations (e.g., flood-proof buildings) and/or building retrofitting;

(v) Land use planning to reduce exposure, including focusing new development away from the floodplain, and preserving space for future infrastructure development;

(vi) Selective relocation away from existing city areas to reduce exposure more rapidly than is possible by only focussing on new development.

(vii) Risk sharing through insurance and reinsurance.

Although it is possible, albeit expensive and problematic, to relocate large numbers of people and city infrastructure (including port facilities, see Garcia 2008) in the near- to medium-term, it is more likely that infrastructure improvement and flood defences are a first choice as they protect against impacts during the most frequent, but less intense, events.

To investigate the protective capacity of defences, the average annual risk of damage, measured in terms of people affected, or assets damaged or affected, was calculated for selected ports: as the defences improve, so the potential damage in an event is distributed over a longer period, and the average annual damages are reduced. Current population and asset exposure were multiplied by the probability of flooding (defence design standard) as a proxy to calculate average annual risks. This risk proxy is not equal to actual risk. This proxy overestimates risk because, in case of floods, losses are lower than the value of flooded exposure. It also underestimates

\footnotetext{
${ }^{5}$ Note: as previously stated the economic scenario does not include climate change impacts or climate policies, which could have a significant influence on GDP and assets in some regions of the world.
} 
risk because exposure is not constant and increases with the flood return period (for instance, the exposure to the 1,000 year flood is larger than to the 100 years used here; see an illustration on Copenhagen in Hallegatte et al. 2011 this volume). It is also worth noting that the average annual risk of damage can be misleading in well defended areas as impacts will be realised infrequently and the impacts per flood event will be much higher than the average annual values. It also ignores the possibility of defence failure which, especially if the failure mechanism involves multiple breaches, can lead to large areas being submerged. Table 4 shows the change in this risk proxy for selected cities where protection levels are known. Without adaptation, the analysis suggests a significant increase in flood risk in all the cities. Detailed case studies in London (Dawson et al. 2005), New York (Rosenzweig and Solecki 2001) and Copenhagen (Hallegatte et al. 2011 this issue) demonstrate that these types of changes are realistic. If defence standards are maintained, flood risk will still rise, but only in proportion to the increase in socio-economic factors. To maintain risk at the levels in 2005 therefore requires more than maintenance of defence standards-in practice the standard has to also be raised.

The achievement of the risk reduction shown in Table 4 relies on the construction and maintenance of physical defence structures and wealth is an important condition of the ability to protect. Cities in rich countries should therefore have more potential to reduce levels of average annual risk than cities in the developing world and GDP can be used as a useful 'vulnerability proxy indicator' (Dao and van Woerden 2009). A simple qualitative classification, based on the 2005 per capita GDP (PPP), can therefore indicate the current ability of the country to adapt its exposed cities against the potential impact of extreme events and recover from disastrous events (following Hoozemans et al. 1993; Nicholls 2004). Classification criteria are broadly in line with the OECD Development Assistance Committee classification (DAC 2006) of country income.

Compared with the number of currently exposed people (Table 5), this GDP classification indicates that of the Top 10 countries, the USA and the Netherlands are considered the most capable of providing comprehensive high level protection against an extreme event. By comparison India, Vietnam and Bangladesh are likely have financial constraints when providing constructed defences, relying on other adaptation methods. Post-event disaster recovery would also be challenging and probably depend on donor support. In total, across the full set of 136 port cities, 26 cities with a total currently exposed population of 11.4 million people (Scenario C) are located in countries classified as 'low income'

However, the willingness to protect population and infrastructure is not purely wealth dependant. Non-financial constraints on the provision of built defences (e.g., collective action possibilities, quality of public policies, role of State) or redistribution of significant resources from other priorities (e.g., transportation) toward flood protection can have a large influence. Rich countries, despite having a larger financial capacity to protect their cities, may or may not choose to do so according to the risk aversion nature of the exposed populations or their governments. For instance, Amsterdam, Rotterdam, London and Tokyo, where GDP per capita is between $\$ 30,000$ and $\$ 38,000$, are protected to better than a 1 in 1,000 year event; Greater New York, in spite of a higher national GDP per capita in the U.S. $(\$ 42,000)$, is protected to a lower standard of about 1 in 100; Shanghai, with the lower Chinese national GDP (PPP) per capita $(\$ 6,193)$, has a better protection level than New York with 


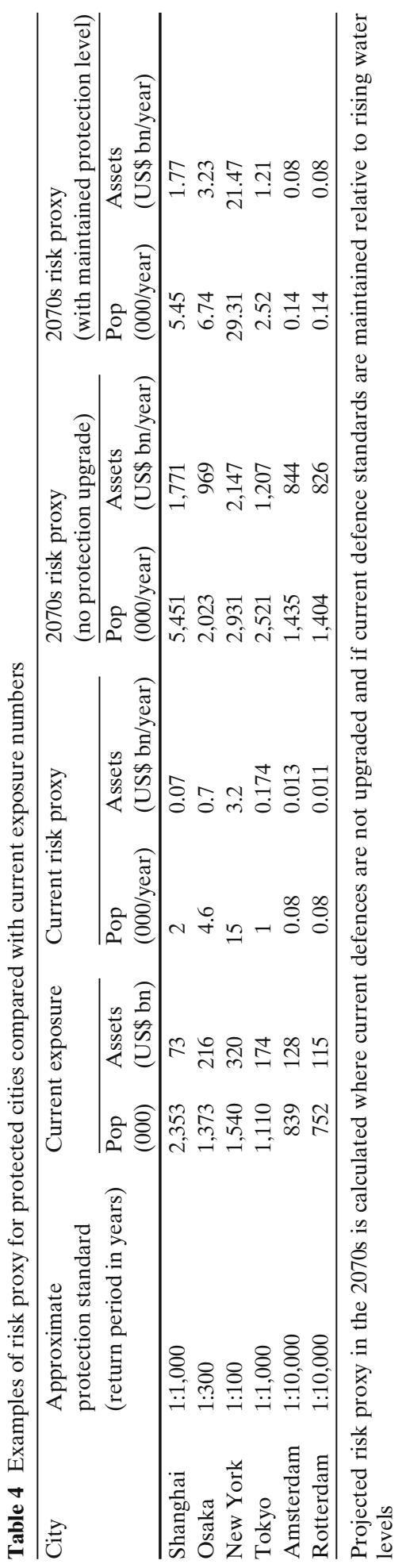


Table 5 Top 10 countries by population currently exposed to a 1:100 extreme event compared to potential to protect

\begin{tabular}{|c|c|c|c|c|}
\hline $\begin{array}{l}\text { Number } \\
\text { of cities }\end{array}$ & $\begin{array}{l}\text { Exposed } \\
\text { population } \\
(000 \mathrm{~s})\end{array}$ & Country & $\begin{array}{l}\text { Per capita } \\
\text { GDP class }\end{array}$ & Presumed protection standard \\
\hline$\overline{15}$ & 8,154 & China & Medium & $\begin{array}{l}\text { Able to afford to construct } \\
\text { defences but not to a uniform, } \\
\text { high standard }\end{array}$ \\
\hline 17 & 6,538 & USA & High & $\begin{array}{l}\text { Able to afford to construct high } \\
\text { level defences }\end{array}$ \\
\hline 6 & 5,412 & India & Low & Limited, ad hoc approach \\
\hline 6 & 3,683 & Japan & High & $\begin{array}{l}\text { Able to afford to construct high } \\
\text { level defences }\end{array}$ \\
\hline 2 & 2,725 & Vietnam & Low & Limited, ad hoc approach \\
\hline 2 & 1,591 & Netherlands & High & $\begin{array}{l}\text { Able to afford to construct high } \\
\text { level defence }\end{array}$ \\
\hline 3 & 1,540 & Bangladesh & Low & Limited, ad hoc approach \\
\hline 1 & 1,330 & Egypt & Medium & Able to afford to construct \\
\hline 1 & 907 & Thailand & Medium & defences but not to a uniform, \\
\hline 4 & 700 & Indonesia & Medium & high standard \\
\hline
\end{tabular}

Per capita GDP (PPP) class in UD\$: high >15,000; medium 15,000-3,500; low $<3,500$

defences of a similar standard to London. These factors also make it problematic to use simple assumptions to project protection levels up to the 2070s. It can be argued that protection levels are likely to be improved at the global scale over time and as wealth increases, but no prediction for a particular city can be easily proposed, especially given the lack of comprehensive data on past investments in coastal flood protection. This is an important issue for further research.

Given that population and economic growth on the coastal 100-year flood plain is typically the dominant driver of increases in exposure, this implies that riskaverse land-planning and development would be a beneficial approach to curtailing future increases in risk. This might include for example, developing new properties in regions away from the coastal flood plain. However, there are several economic advantages of building in these regions. Planners should weigh up these benefits against the risks involved in building on coastal flood plains and the costs of protective measures.

It should also be remembered that, in addition to reducing risks, it is possible to mitigate the drivers of exposure i.e. by limiting climate change itself or managing human-induced subsidence. For example, this study indicates that the potential impact of human-induced subsidence on the exposure and risk of individual cities is of similar magnitude to storm enhancement and slightly less than sea-level rise. Groundwater extraction and drainage, therefore significantly aggravate the impact of climate change and effective long-term water management strategies to limit this human-induced subsidence can provide significant advantages in terms of risk management for the future. 


\section{Policy implications}

The policy implications of these results depend on many parameters, including population risk aversion and broader policy goals (e.g., priority attributed to poverty reduction and disaster risk reduction). However, these results suggest that the benefits of climate change policies at the city-scale are potentially significant, with policies necessarily including both global mitigation and local adaptation. It is important to remember that, even if all cities are well protected against extreme events, large-scale city flooding may remain frequent at the global scale as so many cities are located in low-lying areas. For instance, assuming that flooding events are independent, there is a $74 \%$ chance of having one or more of the 136 cities affected by a 100 -year event every year, and a $99.9 \%$ chance of having at least one city affected by such an event over a 5-year period. At the global scale, 100-year and even 1,000year events will affect individual large port cities frequently. Hence, even taking an optimistic view and assuming that high protection levels will be provided everywhere in the future, the large exposure in terms of population and assets is still likely to translate into recurring city-scale disasters at the global scale. This makes it essential to consider adaptation as well as disaster planning and management strategies to determine acceptable levels of risk and, perhaps more importantly, address what happens when adaptation and especially defences fail.

Another key result is that future socio-economic changes are important drivers of the global and regional increase in both population and asset exposure. This is particularly important for developing regions where population numbers are expected to rise significantly. For developed countries (where population and economic growth are expected to be smaller), environmental factors are proportionately more important. This is consistent with earlier analyses (e.g. Nicholls 2002; Nicholls et al. 1999). Consequently coastal cities will face great challenges in managing the growth in exposure that will come about from both human and environmental influences, including climate change. The size and concentration of population and economic development in many of the world's largest port cities highlights the need for more effective governance for climate change adaptation at the city-scale. The large potential port city asset exposure on its own (i.e. up to US $\$ 35,000$ billion in 2070s, in PPP, 2001USD) argues for a much more focused effort across all scales of governance-from global to national and local, across public and private actors-to advance portfolios of adaptations to manage these risks in port cities (cf. Evans et al. 2004; Thorne et al. 2007, see also Corfee-Morlot et al. 2011 this issue).

Aside from global mitigation of climate change, adaptation to reduce risks is an obvious strategy. While there are many available coastal adaptation options (Klein et al. 2001), the most effective adaptation policy options include a combination of the approaches described in Section 4. For human-induced subsidence the increased risk could be mitigated to some degree by avoiding the processes that lead to shallow subsidence, such as groundwater withdrawal, alongside urban water demand management. Several Asian cities appear to have successfully implemented such water management policies including Tokyo, Osaka-Kobe and Shanghai (Nicholls 1995) with others starting to address the issue, e.g. Jakarta (Delinom 2008). Relocation seems unlikely for valuable city infrastructure, considering the cost of rebuilding infrastructure and buildings (e.g., more than $\$ 400$ billion in Miami today), and 
the political difficulties to do so (illustrated by the public outcry after the French government suggested the destruction of 1,500 houses in the highest-risk areas affected by storm Xynthia in 2010). As a consequence, a portfolio of the other approaches could act to manage and reduce risks to acceptable levels. For cities with large areas at or below mean sea level, flooding can be catastrophic as the urban areas need to be pumped dry after a flood, as illustrated in New Orleans in 2005. If cities remain in these areas, the residual risk needs to be carefully evaluated and defences and drainage carefully reviewed and improved to maintain acceptable standards of risk management: two cities where this issue is relevant today is Guangzhou and Alexandria, but the issue is likely to become more widespread through the twentyfirst century. Proactive adaptation will require strengthening adaptive management and governance capacity to manage increasing risks in port cities. This must include more effective partnerships with national governments and other stakeholders to facilitate the transition towards safe urban development in large port cities and to eventual disaster management in the event of flooding.

Also, the increase in exposure (and probably in risk) may have important consequences on the insurance and reinsurance markets, with a huge increase in the amount of capital needed to insure these risks at the global scale.

Working in partnership, local and national decision-makers will bring greater resources and expertise to bear on the adaptation problem; policies will be needed to establish incentives for public and private investors (see Corfee-Morlot et al. 2011 this issue). National governments are uniquely well-placed to assist port city adaptation efforts by bringing available research to bear on specific locations to better understand the nature of the risks in local contexts and the costs and benefits of adaptation, and to facilitate the development of risk sharing approaches and insurance markets. Local governments on the other hand will need to work closely with local stakeholders and decision-makers to assess and choose amongst available adaptation options to reflect acceptable risk levels and balance the interests of those most directly affected.

Interactions between national and city-level decision-makers, public and private, as well as national and often international policymakers (i.e. where relevant official development assistance) inevitably shape the way cities and city infrastructure develops (OECD 2006). Table 4 illustrates that these decisions on how and where cities develop will make a difference to the exposure of cities to coastal flood risk. Climate change will exacerbate the pressures of population and economic exposure in port cities, especially if cities expand into high flood risk areas. Broad engagement across scales of governance and different types of actors will be necessary to protect against and to manage coastal flood risk.

\section{Conclusion}

This global screening study relies on simple methodologies and does not provide a prediction of how coastal flood risks will change in the future. But it makes a first estimate of the exposure of the world's 136 large port cities to coastal flooding due to extreme water level events. The analysis focused on the exposure of population and assets to a 1 in 100 year surge-induced flood event (assuming no defences), rather than the actual 'risk' of coastal flooding, recognising that flood protection 
does not eliminate risk as protection measures can fail. As such, it has identified those port cities with the highest levels of population and asset exposure both today and looking at how they might change by the 2070s using "business-as-usual" socioeconomic projections and reasonable scenarios of changes in extreme water levels. In spite of the large uncertainty in these scenarios, the magnitude of this exposure has highlighted that port cities will face challenges in managing the significant growth in exposure that will come about from both human and environmental influences, including human-induced and natural subsidence and climate change. It is also important to note that even if the environmental or socio-economic changes were smaller than assumed here the underlying trends would remain.

Although the city exposures identified are necessarily imprecise due to the source data and methodology used, and to scenario uncertainty, a high impact potential in this study indicates those cities where detailed investigation of the possible impacts would be beneficial. However, as the uncertainties in the methodology are unbiased, the aggregated national, continental and global results are considered increasingly robust (cf. Hoozemans et al. 1993). The importance in global trade of these port cities also means that failure to develop effective adaptation strategies would inevitably have local, national and wider economic and security consequences: therefore local strategies will need to be incorporated within a wider spatial and time frame to address broader issues. The concentration of future exposure to sea level rise and storm surge in rapidly growing cities in developing countries in Asia, Africa and to a lesser extent Latin America, also urgently underscores the need to integrate the consideration of climate change into long-term coastal flood risk management and disaster planning, rather on more immediate reactive responses.

As with any study, it is important to recognise and understand limitations in the methodology. The city data is derived from global datasets and these are subject to large uncertainties inherent in such sources. Data constraints also arise from the limited resolution of the elevation data and use of global sea-level values. Future work could improve this analysis through the use of more precise datasets, including regional differences in sea level changes. In terms of methods, the flooding analysis is based on elevation data only, with no modelling of water propagation and dynamics. It is well known that damages depend on water dynamics (e.g. water velocity) and flood duration. The nature of city buildings and infrastructure is also not explicitly considered: people/assets in skyscrapers are not at the same risk as people/assets in single story buildings. Since the focus is on ranking exposure, these limitations remain acceptable and the rankings provide a basis for targeting further more detailed cityscale investigations in key locations.

In addition, this study has also has highlighted where additional investigations would be beneficial: similar independent or integrated assessment for other aspects of climate change, further investigation of the influence of defences on exposure levels and the desire for their construction-the ability to afford any adaptation measure does not necessarily equate to the willingness to undertake the adaptation option, how is an acceptable level of risk determined.

Despite the recognised limitations, this study emphasises the concentration of exposure in a few of the world's cities and nations and underscores the urgent need for leadership and attention in these locations. However, implementing effective disaster management strategies, land use practices and protection investments will take time. Previous defence projects (e.g., the Thames Barrier and the Dutch Delta 
Project) have shown that realising coastal protection infrastructure typically has a lead-time of 30 years or more. Such inertia in the policy and socio-economic response suggests that decisions to protect port cities and to manage flood risk for impacts expected by the middle of this century need to be made and realised today.

\section{References}

Burniaux J-C, Chateau J (2008) An overview of the OECD Env-linkages model. Organisation for Economic Co-operation and Development (OECD), Paris

Corfee-Morlot J, Cochran I, Hallegatte S, Teasdale P-J (2011) Multilevel risk governance and urban adaptation policy. Clim Change. doi:10.1007/s10584-010-9980-9

DAC (2006) List of aid recipients. Development Assistance Committee (DAC) of the Organization for Economic Cooperation and Development (OECD), Paris

Dao H, van Woerden J (2009) Population data for climate change analysis. In: Guzmán JM, Martine G, McGranahan G, Schensul D, Tacoli C (eds) Population dynamics and climate change. United Nations Population Fund and International Institute for Environment and Development, New York

Dawson RJ, Hall JW, Bates PD, Nicholls RJ (2005) Quantified analysis of the probability of flooding in the Thames Estuary under imaginable worst case sea-level rise scenarios. Int J Water Resourc Dev 21:577-591

Delinom RM (2008) Groundwater management issues in the Greater Jakarta area, Indonesia. TERC Bull, University of Tsukuba 8(2):40-54

Dixon TH, Amelung F, Ferretti A, Novali F, Rocca F, Dokka R, Sella G, Kim S-W, Wdowinski S, Whitman D (2006) Subsidence and flooding in New Orleans. Nature 441:587-588

Evans E, Ashley RM, Hall J, Penning-Rowsell E, Saul A, Sayers P, Thorne C, Watkinson A (2004) 'Foresight', future flooding scientific summary, vol I and II. Office of Science and Technology (OST), London

Fisher BS, Nakicenovic N, Alfsen K, Corfee Morlot J, de la Chesnaye F, Hourcade J-C, Jiang K, Kainuma M, La Rovere E, Matysek A, Rana A, Riahi K, Richels R, Rose S, van Vuuren D, Warren R (2007) Issues related to mitigation in the long term context. In: Metz B, Davidson OR, Bosch PR, Dave R, Meyer LA (eds) Climate change 2007: mitigation. Contribution of working group III to the fourth assessment report of the Inter-Governmental Panel on Climate Change. Cambridge University Press, Cambridge

Garcia PR (2008) The role of the port authority and the municipality in port transformation: Barcelona, San Francisco and Lisbon. Plan Perspect 23:49-79

Grossi P, Muir-Wood R (2006) Flood risk in New Orleans: implications for future management and insurability. Risk Management Solutions (RMS), London

Guzmán JM, Martine G, McGranahan G, Schensul D, Tacoli C (eds) (2009) Population dynamics and climate change. United Nations Population Fund and International Institute for Environment and Development, New York

Hallegatte S (2008) An adaptive regional input-output model and its application to the assessment of the economic cost of Katrina. Risk Anal 28(3):779-799. doi:10.1111/j.1539-6924.2008.01046

Hallegatte S, Ranger N, Mestre O, Dumas P, Corfee Morlot J, Herweijer C, Muir Wood R (2011) Assessing climate change impacts, sea-level rise and storm surge risk in port cities: A case study on Copenhagen. Clim Change. doi:10.1007/s10584-010-9978-3

Hoozemans FMJ, Marchand M, Pennekamp HA (1993) A global vulnerability analysis: vulnerability assessment for population, coastal wetlands and rice production on a global scale, 2nd edition. Delft Hydraulics and Ministry of Transport, Public Works and Water Management. The Hague, The Netherlands

IPCC (2007) Summary for policymakers. In: Solomon S, Qin D, Manning M, Chen Z, Marquis M, Averyt KB, Tignor M, Miller HL (eds) Climate change 2007: the physical science basis. Contribution of working group I to the fourth assessment report of the Intergovernmental Panel on Climate Change. Cambridge University Press, Cambridge

Klein RJT, Nicholls RJ, Ragoonaden S, Capobianco M, Aston J, Buckley EN (2001) Technological options for adaptation to climate change in coastal zones. J Coast Res 17:531-543

Leatherman SP, Kershaw P (2002) Sea level rise and coastal disasters. National Academies Press, Washington 
McGranahan G, Balk D, Anderson B (2007) The rising tide: assessing the risks of climate change and human settlements in low elevation coastal zones. Environ Urban 19:17-37

Muir Wood R, Bateman W (2005) Uncertainties and constraints on breaching and their implications for flood loss estimation. Philos Trans R Soc Lond A 363:1423-1430

Munich Re (2004) Megacities, Megarisks. Münchener Rückversicherungs-Gesellschaft, Munich

Nicholls RJ (1995) Coastal megacities and climate change. Geojournal 37:369-379

Nicholls RJ (2002) Analysis of global impacts of sea-level rise: a case study of flooding. Phys Chem Earth 27:1455-1466

Nicholls RJ (2004) Global flooding and wetland loss in the 21st century: changes under the SRES climate and socio-economic scenarios. Glob Environ Chang 14:69-86

Nicholls RJ, Hanson S, Herweijer C, Patmore N, Hallegatte S, Corfee-Morlot J, Chateau J, Muir-Wood R (2007) Ranking port cities with high exposure and vulnerability to climate extremes-exposure estimates. Environmental Working Paper No 1, Organisation for Economic Co-operation and Development (OECD), Paris

Nicholls RJ, Hoozemans FMJ, Marchand M (1999) Increasing flood risk and wetland losses due to global sea-level rise: regional and global analyses. Glob Environ Change 9:S69-S87

OECD (2006) Competitive cities in the global economy. Organisation for Economic Co-operation and Development (OECD), Paris

OECD (2008) OECD Environmental Outlook to 2030. Organisation for Economic Co-operation and Development (OECD), Paris

Rahmstorf S (2007) A semi-empirical approach to projecting future sea-level rise. Science 315:368370

Rosenzweig C, Solecki WD (2001) Climate change and a global city; the potential consequences of climate variability and change-Metro East Coast. Report for the US Global Change Program, National Assessment of the Potential Consequences of Climate variability and Change for the United States, Columbia Earth Institute, New York

Sabesan A, Abercrombie K, Ganguly AR, Bhaduri B, Bright EA, Coleman PR (2007) Metrics for the comparative analysis of geospatial datasets with applications to high-resolution grid-based population data. Geojournal 69:81-91

Small C, Nicholls RJ (2003) A global analysis of human settlement in coastal zones. J Coast Res 19:584-599

Solomon S, Qin D, Manning M, Chen Z, Marquis M, Averyt KB, Tignor M, Miller HL (eds) (2007) Climate change 2007: the physical science basis. Cambridge University Press, Cambridge, p 996

Thorne C, Evans E, Penning-Rowsell E (eds) (2007) Future flooding and coastal erosion risks. Thomas Telford, London, p 350

UNFPA (2007) Unleashing the potential of urban growth. State of world population 2007, United Nations Population Fund, New York

UNCTAD (2008) Review of maritime transport. United Nations Conference on Trade and Development (UNCTAD), New York

United Nations (2004a) World population to 2300. United Nations, New York

United Nations (2004b) World population prospects. The 2004 revision. United Nations, New York United Nations (2005) World urbanization prospects. The 2005 revision. United Nations, New York

Vafeidis AT, Nicholls RJ, McFadden L, Tol RSJ, Hinkel J, Spencer T, Grassff PS, Boot G, Klein RJT (2008) A new global coastal database for impact and vulnerability analysis to sea-level rise. J Coast Res 24:917-924

Wigley TML (2005) The climate change commitment. Science 307:1766-1769

Wilbanks T, Romero-Lankao P, Berkhout F, Ceron J-P, Cairncross S, Bao M, Kapshe M, MuirWood R, Zapata-Marti R (2007) Industry, settlement and society. In Parry ML, Canziani OF, Palutikof JP, van der Linden P, Hanson CE (eds) Climate change 2007: impacts, adaptation and vulnerability. Contribution of working group II to the fourth assessment report of the Intergovermental Panel on Climate Change. Cambridge University Press, Cambridge, pp 357390 